\title{
Estudo de traços de argamassa, utilizando escória de aciaria elétrica para produção de argamassa
}

\section{Study of mortar traits using electric arc furnace slag for parget production}

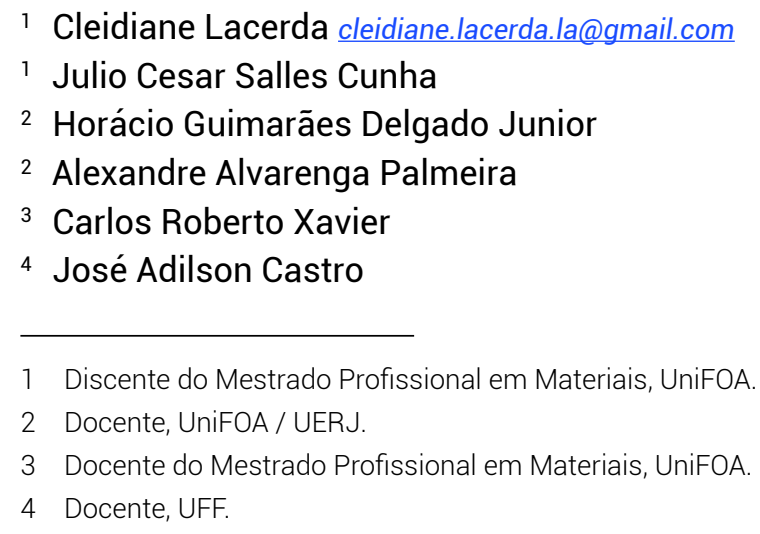

\section{Resumo}

O presente estudo objetivou avaliar a utilização da escória de aciaria elétrica como alternativa aos agregados da argamassa de cimento. Foram avaliadas as propriedades do estado endurecido, em idades de 7 e 28 dias, da argamassa de cimento e areia, tomada como referência, e com substituição em volume nos percentuais de $12,5 \%, 25 \%$ e $50 \%$ da areia por escória de aciaria elétrica, mantendo-se a mesma relação água/cimento em todos os traços. 0 aumento do percentual de escória ocasionou uma maior porosidade na argamassa, porém não há uma retenção de água. Com o objetivo de apontar a viabilidade técnica da utilização da escória de aciaria elétrica como adição argamassa convencional, utilizou-se os ensaios de determinação da resistência à compressão, segundo a NBR 7215 (ABNT, 1995) e de determinação da resistência à tração por compressão diametral de corpos de prova cilíndricos, segundo a NBR 7222 (ABNT, 1994). Os resultados deste estudo revelam o uso potencial da escória de aciaria elétrica, no sentido de conferir à argamassa aumento da capacidade de absorção de água, porém sem retenção e com redução relativamente pequena de resistência à compressão, principalmente em $25 \%$ de substituição de areia.

\section{Palavras-chave}

Argamassa; resíduo siderúrgico; escória.

\begin{abstract}
This study aimed to evaluate the use of electric arc furnace slag as an alternative to cement mortar aggregates. The properties of hardened mortar, at ages of 7 and 28 days of cement and sand mortar, which were taken as reference, and replacing the volume percentage of $12,5 \%, 25 \%$ and $50 \%$ of the sand particles for electric furnace slag, maintaining the same water / cement ratio for all composites were evaluated. Increased slag caused a greater percentage of porosity in the mortar, but there was no water retention. In order to point out the technical feasibility of using electric arc furnace slag as addition to conventional mortar, testing for determining compressive strength was used, according to NBR 7215 (ABNT, 1995), and for determining the tensile strength by diametrical compression cylindrical sample according to NBR 7222 (ABNT, 1994). The results of this study reveal the potential use of electric arc furnace slag, in order to impart to mortar increased water absorbency, but without restraint and relatively small reduction in compressive strength, especially at $25 \%$ substitution of sand.
\end{abstract}

\section{Keywords}

Mortar; waste steel; slag.

\section{Como você deve citar?}

LACERDA, Cleidiane et al. Estudo de traços de argamassa, utilizando escória de aciaria elétrica para produção de argamassa. Cadernos UniFOA, Volta Redonda, n. 31, p. 13-21, ago. 2016. 


\section{INTRODUÇÃO}

O aproveitamento de resíduos como materiais alternativos na construção Civil vem se tornando frequente, visto que os rejeitos, sejam industriais ou urbanos, acabam por poluir o meio ambiente, causando problemas de armazenagem ou descarte de certos produtos.

Os padrões de identificação e de descarte de resíduos industriais variam sensivelmente entre os países. Praticamente todas as nações industrializadas têm revisto e tornado mais restritivas suas legislações ambientais, em especial no que concerne à produção, ao transporte, ao tratamento e à deposição final dos resíduos industriais. (GEYER, 2001)

Dentro de um processo, não é diferente a escória, que dentro dos processos pirometalúrgicos, além da fase líquida constituída pelo banho metálico, está quase sempre presente uma fase líquida de natureza não metálica (LÚCIO, 1981), normalmente destinada ao pátio de armazenamento dentro do parque fabril, para posterior descarte.

Pelo simples fato de que a siderurgia lida diariamente com quantidades imensas de matérias-primas e energia, o seu impacto ambiental sempre foi importante. Nas usinas, os esforços para reduzir emissões e efluentes tendem a passar da mera captação e tratamento à adoção de novas tecnologias de produção, menos poluentes e mais eficientes em termos energéticos. 0 trabalho para preservar 0 meio ambiente se faz e continuará a se realizar de quatro maneiras: obedecendo à legislação ambiental; implementando medidas de conservação de energia; reciclando e conservando os recursos naturais; buscando novas tecnologias, menos poluidoras (PEREIRA, 1994).

O Brasil é, hoje, o $9^{\circ}$ maior produtor de aço no mundo, o que o coloca numa posição estratégica no cenário mundial. Em 2012, foram produzidas 34,5 milhões de toneladas de aço e o setor foi responsável por 4\% do PIB (Produto Interno Bruto) do país (PwC Brasil, 2012). Essa fonte contínua de produção gera, atualmente, aproximadamente 6 milhões de toneladas/ano de escória de aciaria.

A disposição da escória de aciaria está se tornando cada vez mais difícil ambiental e economicamente para o produtor de aço. Ao usarmos coprodutos na construção ou em toda indústria, o potencial de aplicação do material cresce devido à substituição aos recursos naturais.

Sendo assim, a reciclagem de resíduos industriais representa um componente primordial do esforço para um desenvolvimento sustentável. Além disso, guarda uma relação econômica legais de descarte, cada vez mais restritivas.

Este trabalho propõe um estudo de viabilidade de utilização de escória de aciaria elétrica na argamassa endurecida, em substituição percentual à areia, com estudo de resistência mecânica, absorção de água e microscopia, já que ainda são poucos conhecidos os estudos utilizando agregados em argamassa.

\section{MÉTODOS}

Com o objetivo de apontar a viabilidade técnica da utilização da escória de aciaria elétrica como adição argamassa, foram utilizados os ensaios referência dentro construção civil, conforme abaixo:

- Determinação da resistência à compressão, segundo a NBR 7215 (ABNT, 1995). Essa norma também determina a moldagem e compressão de corpos de prova de argamassa. 
- Determinação da resistência à tração por compressão diametral de corpos de prova cilíndricos, segundo a NBR 7222 (ABNT, 1994).

- Determinação da absorção de água por imersão, na qual foi determinada a absorção de água dos corpos de argamassa, segundo a NBR 9778 (ABNT, 1987).

A moldagem e a resistência à compressão de corpos de prova de argamassa, segundo a NBR 7215 (ABNT, 1995), compreende a determinação da resistência à compressão de corpos de prova cilíndricos de $50 \mathrm{~mm}$ de diâmetro e $100 \mathrm{~mm}$ de altura.

Os corpos de prova são elaborados com argamassa composta de uma parte de cimento, três de areia normalizada, em massa, e com relação água/cimento de 0,48 . Porém, para a viabilização da utilização da escória, foram substituídos percentuais de escória na areia, em 12,5\%, 25\% e 50\%, conforme tabela 1.

Tabela 1- Proporções de adição de escórias em relação à areia

\begin{tabular}{ccc} 
\% de escória & Proporção areia/cimento & No de corpos de prova \\
\hline 0 & $03: 01$ & 3 \\
\hline 12,5 & $03: 01$ & 3 \\
\hline 25 & $03: 01$ & 3 \\
\hline 50 & $03: 01$ & 3 \\
\hline
\end{tabular}

A cura dos corpos de prova foi inicial ao ar, em câmara úmida durante 20 a 24 h e, a cura final, em tanque de água saturada de cal, se deu até a idade de cura, de acordo com a NBR 7215 (ABNT, 1996). As idades de cura definidas para os ensaios foram 7 e 28 dias.

Para os ensaios de resistência à compressão e de resistência à tração por compressão diametral, as amostras, após a cura final, foram submetidas a uma prensa hidráulica EMIC, PC $100 \mathrm{C}$ com capacidade de $100.000 \mathrm{kgf}$, disponível no laboratório da UniFOA (Volta Redonda-RJ), em carga contínua até a ruptura.

O resultado final da resistência à tração por compressão diametral foi calculado pela seguinte expressão:

$f_{t, D}=\frac{2 . F}{p . d . L}$ Onde:

$f_{t, D}=$ resistência à tração por compressão diametral, expressa em MPa, com aproximação de 0,05 MPa;

$F=$ carga máxima obtida no ensaio $(\mathrm{kN})$;

$d$ = diâmetro do corpo de prova $(\mathrm{mm})$;

$L=$ altura do corpo de prova $(\mathrm{mm})$.

Os fragmentos dos corpos de prova recuperados do ensaio de resistência à compressão foram submetidos a um estudo de caracterização da microestrutura, por meio da técnica de microscopia eletrônica de varredura. As micrografias foram obtidas em um Microscópio Eletrônico de Varredura HITACHI, TM 3000, disponível no laboratório da UniFOA (Volta Redonda-RJ). 


\section{RESULTADOS}

Podemos observar, na figura 1, que há uma diminuição dos valores de resistência à compressão, à medida que se aumenta o percentual de escória na areia, cerca de $8,8 \mathrm{Mpa}$ de média de $0 \%$ para $50 \%$ de adição de escória à mistura.

Figura 1- Avaliação de aumento de proporção de escoria $X$ relação de resistência à compressão (idade: 7 dias)

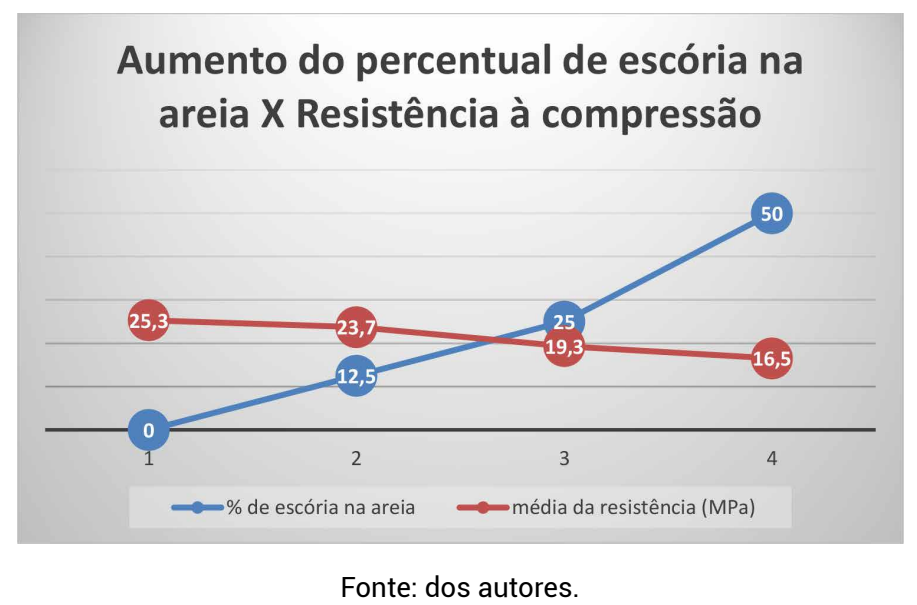

Constatou-se, conforme figura 2, que as amostras de 28 dias têm valores mais estáveis e maior valor de resistência que as amostras de 7 dias e a variação de resistência é a metade, comparada a idade de 7 dias.

Figura 2- Avaliação de aumento de proporção de escoria $X$ relação de resistência à compressão (idade: 7 dias)

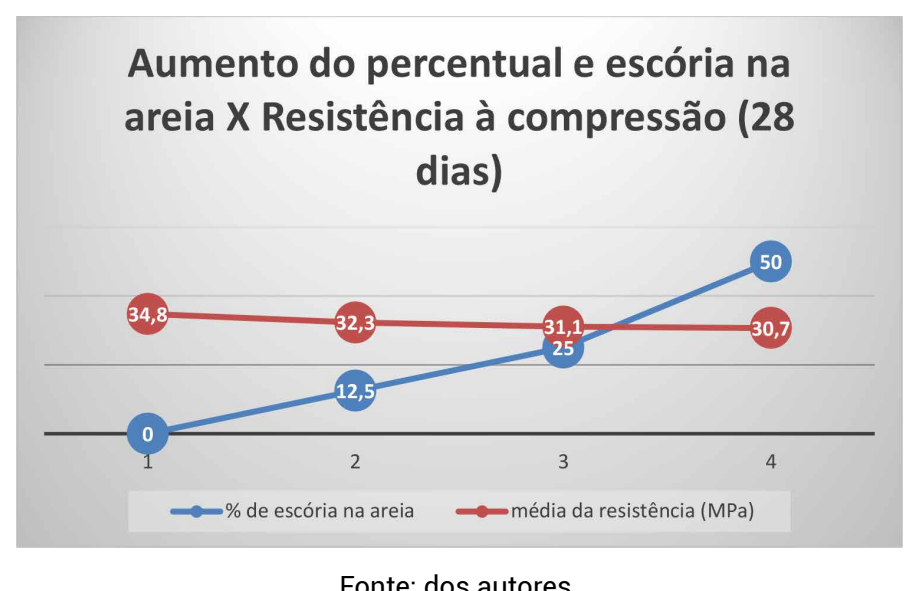

Nos ensaios de compressão diametral em amostras de 7 dias de cura, constatou-se, conforme apontado na figura 3, que os valores de resistência tração, quando se substitui $12,5 \%$ de areia por escória, em torno de 0,34Mpa, há uma diminuição dos valores de tração, quando se substitui $12,5 \%$ de areia por escória, em torno de 0,34Mpa. Os corpos de prova de $25 \%$ de adição de escória aumentam significativamente os valores em relação a $12,5 \%$ e a $0 \%, 1,74 \mathrm{MPa}$ e 1,4 Mpa, respectivamente. 
Figura 3 - Análise gráfica da resistência à compressão diametral - 7 dias

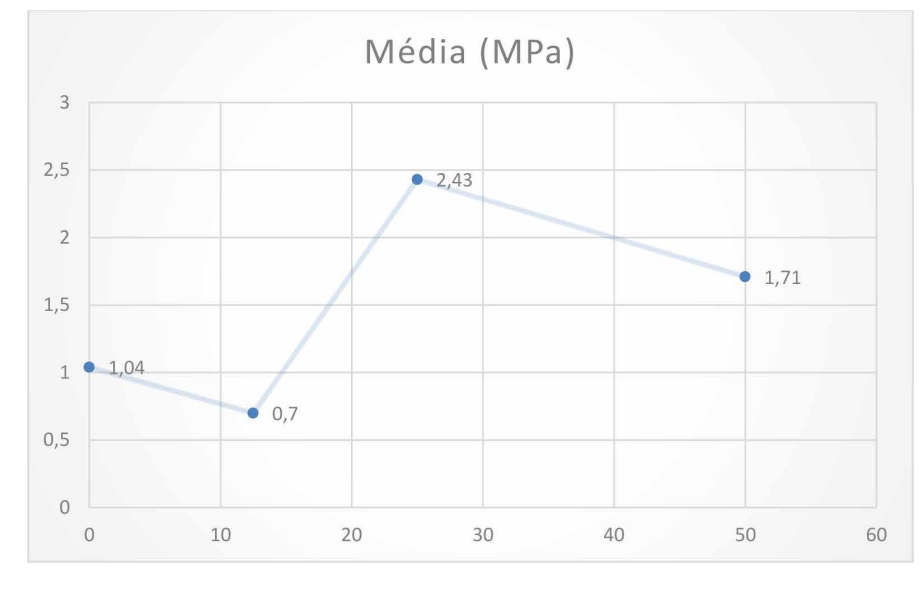

Fonte: dos autores.

Nos ensaios de compressão diametral em amostra com 28 dias de cura, constatou-se, conforme apontado na figura 4, que há uma diminuição dos valores de resistência, de acordo com o aumento percentual de adição escória na areia, cerca de 0,83 Mpa de média de $0 \%$ para $50 \%$ de adição de escória.

Figura4 - Análise gráfica da resistência à compressão diametral - 28 dias

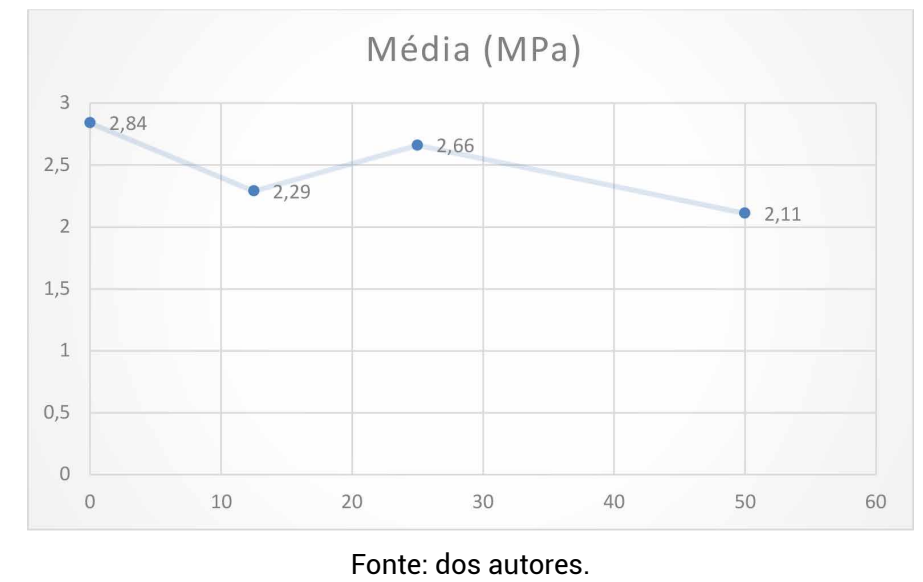

Comparando as duas idades, pode-se observar que as amostras de 28 dias têm valores mais estáveis que as amostras de 7 dias.

Para o ensaio de absorção por imersão, conforme figura 5, observa-se que os corpos com $50 \%$ de escória na areia tem uma redução na absorção de água, na média $0,58 \mathrm{~g}$, bem próximo aos valores dos corpos de prova de $12,5 \%$ e mais baixo em $0,11 \mathrm{~g}$ dos corpos de $25 \%$. 
Figura 4 - Análise gráfica para média absorção de água por percentual de escória.

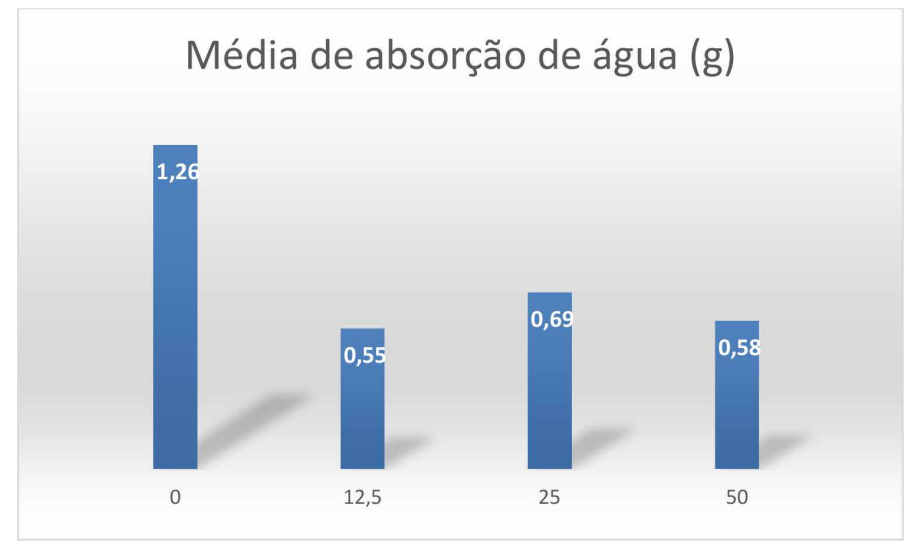

Fonte: dos autores.

Pela técnica da microscopia eletrônica de varredura pode-se observar que sem adição de escória, as partículas mais finas sofrem a formação mineralógica clássica e a interface entre os grãos aglutinadas pelo ligante, visto na figura 5 .

Figura 5 - MEV corpos de 0\% de adição de escória ampliados 1000X.

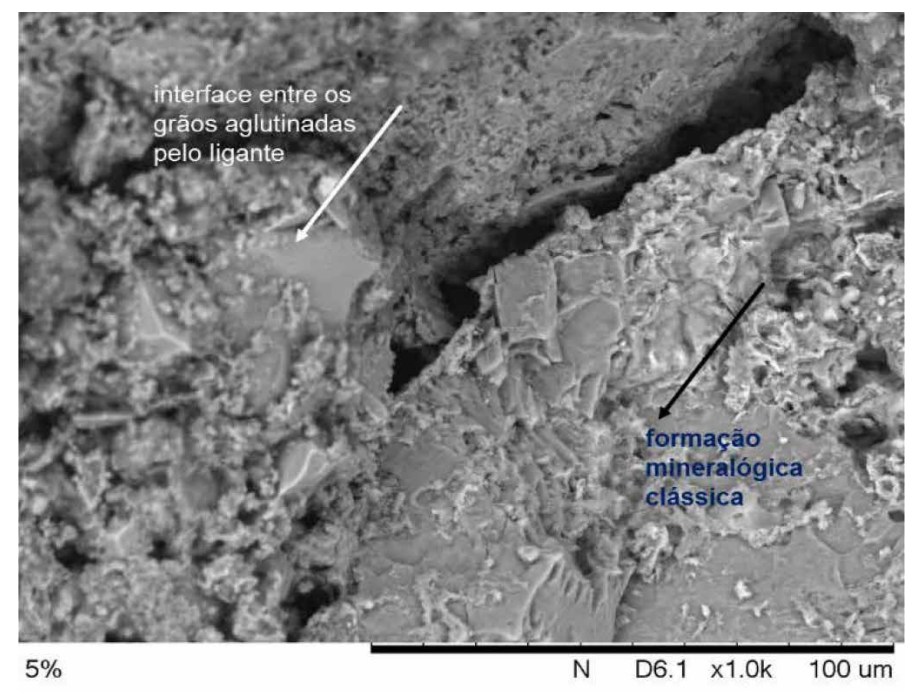

Fonte: dos autores.

Com $12,5 \%$ de proporção, relacionado à areia, observa-se os cristais aderidos às interfaces dos contornos de grão, em face de possível concentração de energia no contorno de grão e a presença de porosidade, podendo ser verificado na figura 6 . 
Figura 6 - MEV corpos de 12,5\% de adição de escória ampliados 500X.

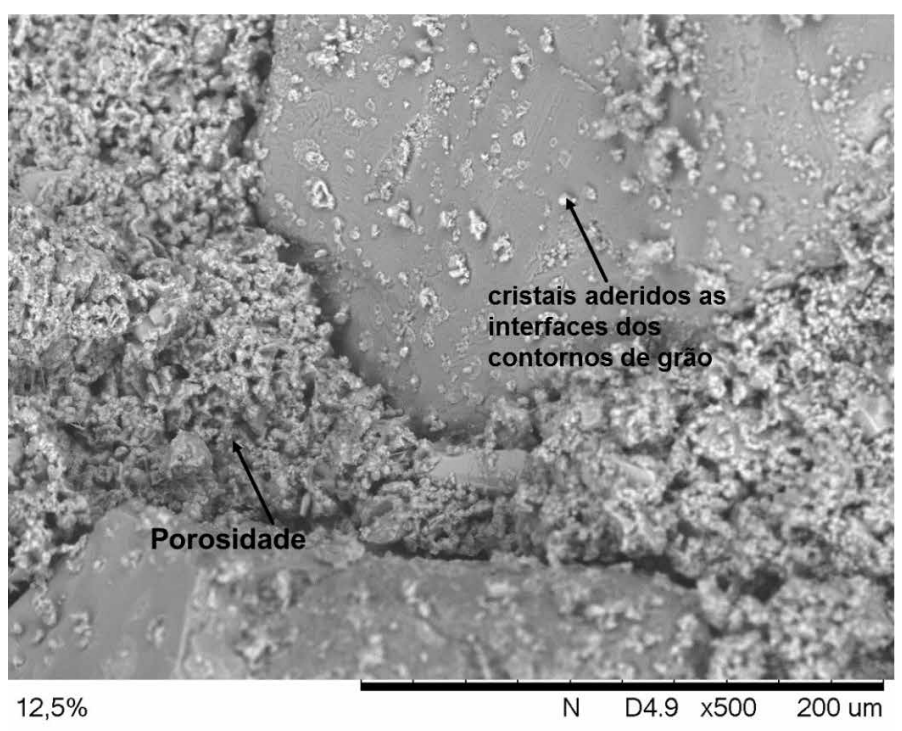

Fonte: dos autores.

A $25 \%$ de adição de escória, pode-se observar a porosidade. Assim, há também uma interação entre areia e escória, conforme mostrado na figura 7.

Figura 7 - MEV corpos de 25\% de adição de escória ampliado 1000X.

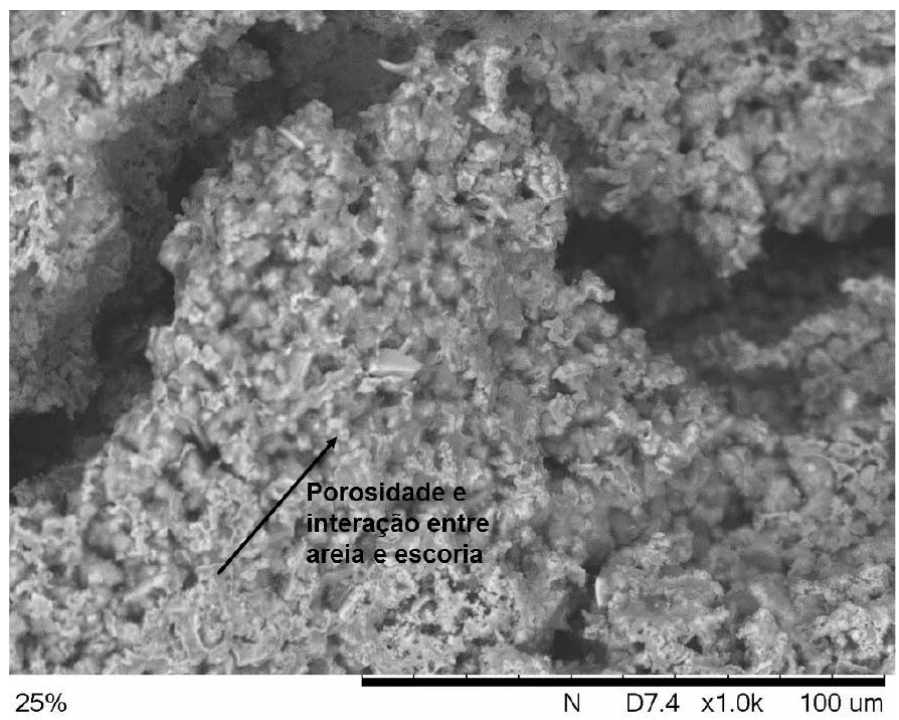

Fonte: dos autores.

Pode-se observar, em $50 \%$ de adição de escória à areia, que a diferença de granulometria da escória é maior que a da areia. E, em 1000X de aumento, observa-se a separação, conforme apontado na figura 8. 
Figura 8 - MEV corpos de 50\% de adição de escória ampliados 1000X.

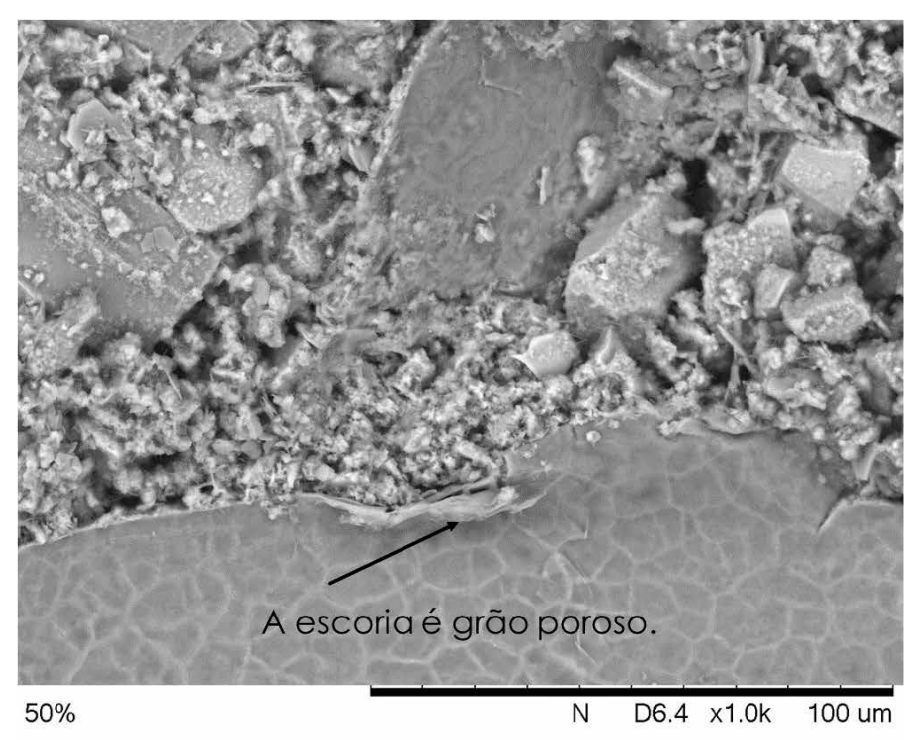

Fonte: dos autores.

\section{CONCLUSÃO}

Quanto aos resultados obtidos nos ensaios dos corpos de prova, podemos chegar às seguintes conclusões:

- o aumento do percentual de escória ocasionou uma maior porosidade na argamassa, porém não houve retenção de água;

- a porosidade em alguns resultados de compressão e tração foram maiores, possivelmente foi devido à propriedade cimentíssia e aglutinante da escória imediata ou curto prazo;

- a resistência mecânica da argamassa com agregado de escória foi inferior à argamassa de referência, em até em 35\% em 7 dias e 12\% em 28 dias à compressão;

- nas argamassas com adição de escória, observa-se os cristais aderidos às interfaces dos contornos de grão, em face de possível concentração de energia no contorno de grão;

- a $25 \%$ de adição de escória, pode-se observar a porosidade. No entanto, ocorreu também uma interação entre areia e escória;

- a escória se mistura ao aglutinante (cimento) e, em alguns casos, fica no contorno de grão;

- para a absorção de água por imersão, a variação de absorção se deu numa média de $\pm 5 \%$.

A partir dos resultados encontrados, pode-se concluir que as adições de escória de aciaria em argamassa possuem características apropriadas para serem reutilizadas e recicladas, principalmente em $25 \%$ de adição, objetivando reduzir os impactos ambientais e econômicos causados pelo descarte de escória em aterros. 
Cleidiane Lacerda / Julio Cesar Salles Cunha / Horácio Guimarães Delgado Junior Alexandre Alvarenga Palmeira / Carlos Roberto Xavier I José Adilson Castro

\section{REFERÊNCIAS}

ABNT. Associação Brasileira de Normas Técnicas. NBR 5.732 - Cimento Portland comum-especificação. Rio de Janeiro, 1991. 5p.

NBR 7.214 - Normal para ensaio de cimento. Rio de janeiro, 1982. 7p.

NBR 7.215 - Cimento Portland: determinação da resistência à compressão. Rio de Janeiro, 1996. 8p.

NBR 7.222 - Argamassa e concreto: determinação da resistência à tração por compressão diametral de corpos-de-prova cilíndricos. Rio de Janeiro, 1994.3p.

GEYER, A. L. B. Estudo sobre a disposição final e potencialidades de aproveitamento das cinzas de lodos de estações de tratamento de esgotos sanitários de Porto Alegre como insumo na produção de concreto. Tese (Doutorado em Engenharia) - Programa de Pós-Graduação em Engenharia Civil. NORIE/ UFGRS, 2000, $165 \mathrm{p}$.

GEYER, R. M. T. Estudo sobre a potencialidade de uso das escórias de aciaria como adição ao concreto. Dissertação para a obtenção do título de Doutor em Engenharia. Universidade Federal do Rio Grande do Sul, 2001, $187 \mathrm{p}$.

GEYER, R. M. T. et al. Escórias Siderúrgicas: caracterização e aplicações para a Indústria da Construção Civil. In: Seminário de Redução e Matérias-Primas Resíduos na Siderurgia, 25. Volta Redonda, RJ. Anais... Volta Redonda, 1994, p.363- 381.

LÚCIO, A. Físico-química metalúrgica - 2ª parte. Belo Horizonte, 1981. p. 555-599.

PEREIRA, E. A. C. Aspectos técnicos da gestão de resíduos nas siderúrgicas integradas a coque. In: Seminário de Redução e Matérias-Primas Resíduos na Siderurgia, 25. Volta Redonda, RJ. Anais. Volta Redonda, 1994, p.187-199. 